\title{
Improving Railway Passengers Experience: Two Perspectives
}

\author{
Mark van Hagen ${ }^{1}$ and Niels van Oort $^{2}$ \\ 1. Research Department, Dutch Railways, PO Box 2025, 2500 HA, Utrecht, the Netherlands \\ 2. Department of Transport and Planning, Delft University of Technology, PO Box 5048, 2600 GA, Delft, the Netherlands
}

\begin{abstract}
This paper describes two perspectives to improve the passenger experience. The passenger satisfaction pyramid is introduced, consisting of the base of the pyramid (dissatisfiers) focusing on time well saved and the top of the pyramid (satisfiers) aiming at time well spent. The challenge in planning and design of public transport services is to find the most efficient (set of) design choices. Depending on the context this might either mean focusing on the top or on the bottom of the pyramid. We found that influencing and enhancing the qualities of the satisfiers is far more important than traditional studies showed us. For stations, regression analyses show that dissatisfiers are responsible for explaining almost half of the total score of the station and satisfiers are responsible for the other half of the scores passengers give for the station. We still have to put a lot of energy in getting the basics right, starting in the planning phase, but then we are not allowed to lean back. We have to keep investing in qualities like ambience, comfort and experience which makes the customers truly happy at the end of the day.
\end{abstract}

Key words: Passenger experience, service reliability, perception, behaviour.

\section{Introduction}

In day-to-day practice railway operators have to compete with the qualities of the car. People wanting to move from one location to another often opt for the path of least resistance, i.e. the cheapest, fastest and most reliable way to travel. With regard to mode choice, travel time and reliability are often found to be the most important aspects [1]. Travellers do not just choose the car or train off-hand but take the entire organization and execution of the trip, both there and back, into consideration [2]. This entails planning the journey, making preparations before departure, checking possible disruptions, etc. Having opted for the train confronts the passengers with a chain of experiences from start to finish, meaning they undergo the entire journey holistically with some phases of the

Corresponding author: Mark van Hagen, Dr., research fields: transport and behavioral sciences. E-mail: mark.vanhagen@ns.nl. journey possibly having quite an emotional impact [3]. Stress and irritation can occur when too much is asked of the passengers. Obviously, the goal is to provide services enabling passenger to experience their travel time in a relaxed and pleasant way, that will say that they experience positive emotions and even be enthusiastic about the train journey. Actually, two elements are important regarding this passenger experience, namely the actual level of service and the perceived quality. The objective of this paper is to combine the current insights into customer satisfaction from these two perspectives, namely the traffic engineering and the psychological perspective. In this way, decisions can be supported and improved, concerning the focus of investments and improvements. The outline of this paper is as follows: the next section presents insights into passenger quality perception and Section 3 shows examples of how to improve it, from two perspectives. Section 4 summarises the main conclusions. 


\section{Customer Needs and Preferences}

\subsection{Travel Time Well Saved and Well Spent}

As stated, travel time and reliability are important but it is not only travel time and its reliability itself; also the way you can use your travel time is important $[4,5]$. Passengers embrace convenience and wish to experience some quality time, so the way they can use their travel time in a useful or pleasant way is also important. Although most operators have a sound perspective on the basic qualities of the train journey, such as safety, reliability, cleanliness and speed, research shows us that these are not enough to create happy customers. Once the basic facilities are in order, you get satisfied customers. But when you make sure that customers also experience a pleasant and relaxing journey you will get happy customers. Fig. 1 shows the two ways travel time can be managed in a train journey:

- To shorten the total travel time (e.g. by shorter waiting times or improving service reliability; horizontal axis in Fig. 1);

- To enhance the quality of the travel time, by making sure passengers can use their travel time in a useful or pleasant way (vertical axis in Fig. 1).

So, enhancing the quality of a customer journey is about time well saved and time well spent.

\subsection{Quality Dimensions}

It is important to know which quality customers expect and what they are prepared to offer to get the quality they want. It helps to define the quality of customer needs in different quality layers. Various transport needs of customers can be ranked according to importance in the shape of a pyramid [6-9]. The pyramid of customer needs reflects the perception of the quality offered by a transport company (Fig. 2).

The base of the pyramid is formed by the basic needs reliability and safety. For passengers, safety particularly means social safety and this is a prerequisite for considering a trip. If potential customers perceive a train trip to be unsafe, they will avoid it. Reliability indicates the degree, to which passengers experience receiving the quality they expect. If the service (train, information, seat, coffee, etc.) is not available when and where customers expect it, they will become dissatisfied and at the end try to avoid using the train. Because time is the scarcest budget of

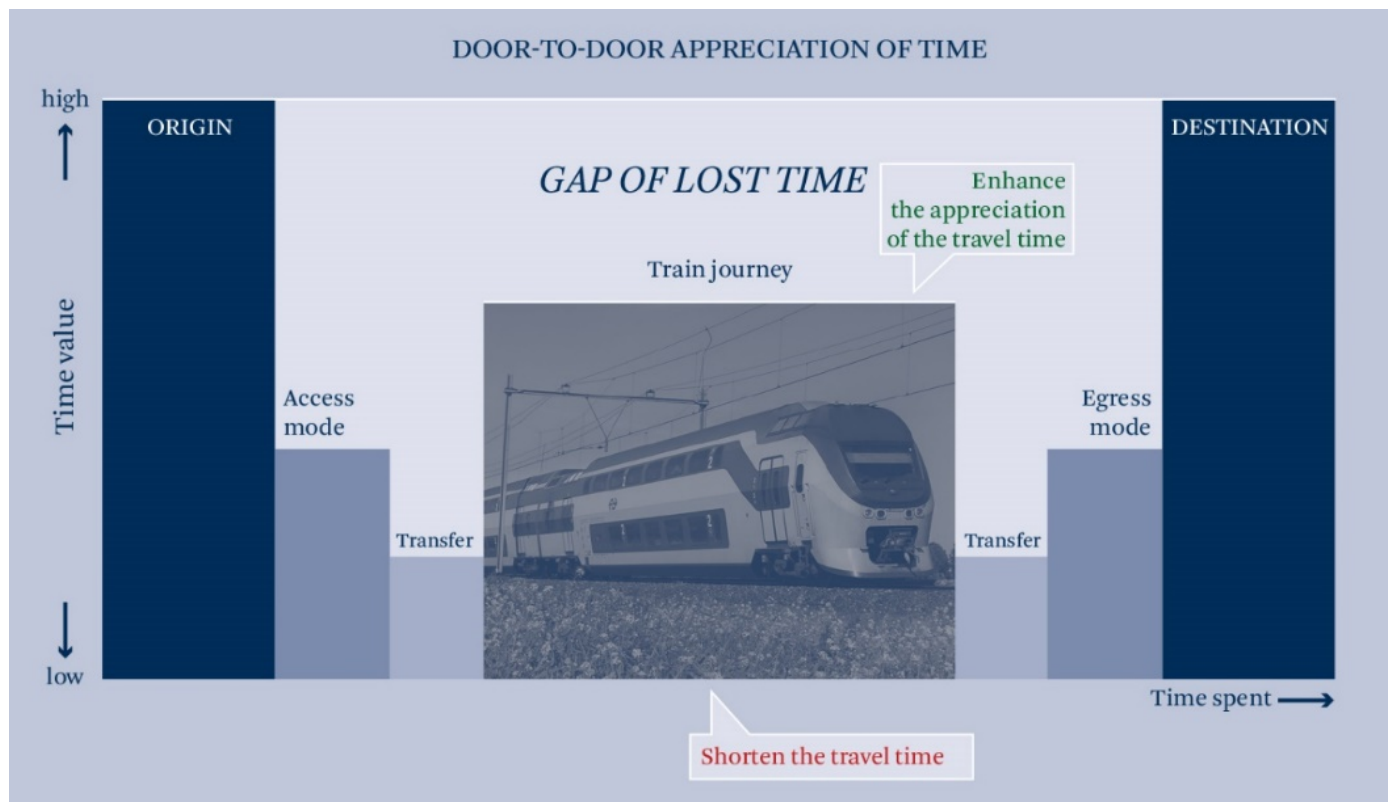

Fig. 1 Two ways to manage the customer journey: shorten the door-door travel time or enhance the appreciation of the travel time. 


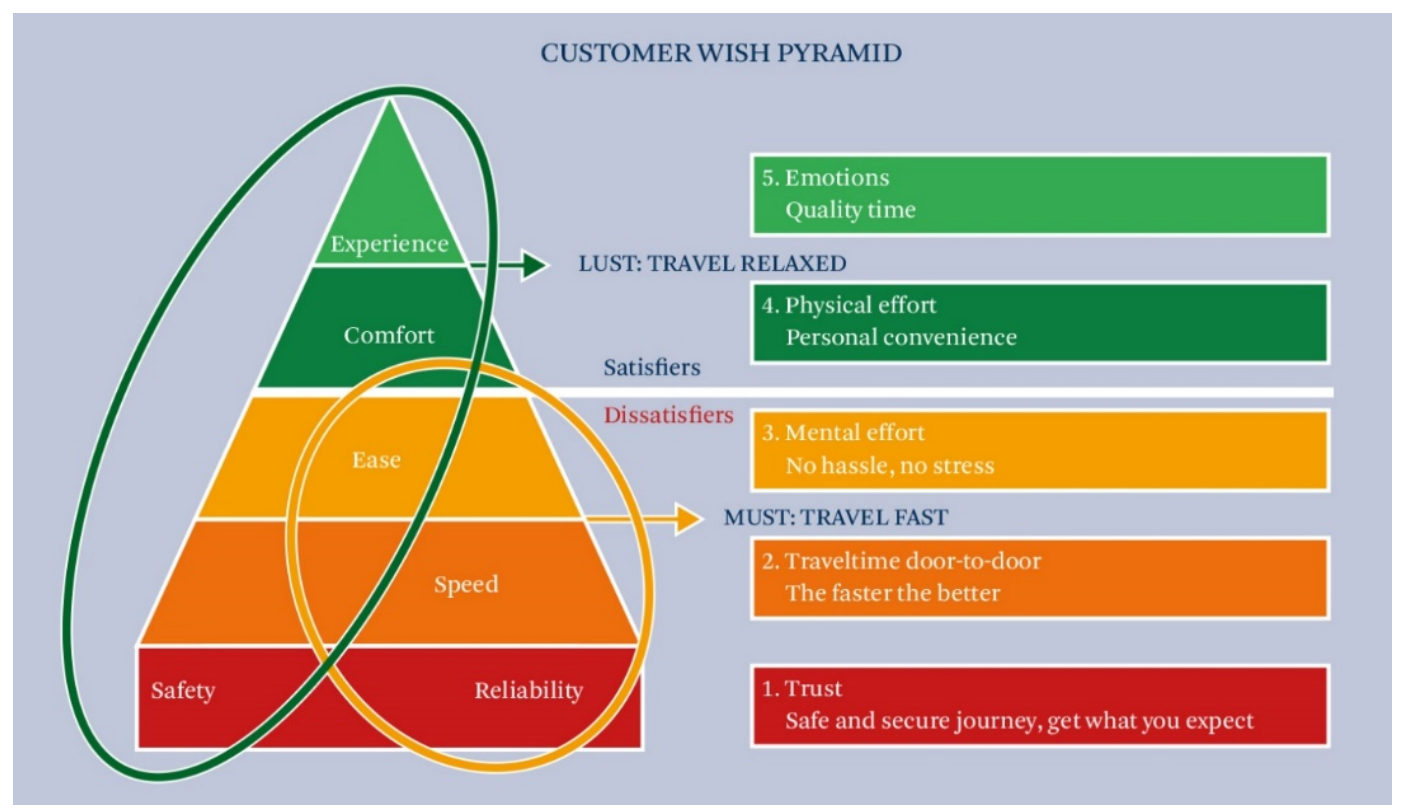

Fig. 2 Quality dimensions in order of importance.

travellers, speed is the principal customer need, i.e. the majority of customers choose the shortest travel time between origin and destination possible. If the condition of a fast journey and transfer has been complied with, then the traveller wants the trip to be easy, i.e. convenient. Good orientation, travel information and signposting are important aids and must be seen as logical and unambiguous. Also the traveller expects a certain degree of physical comfort at the station: sheltered waiting and sitting areas and food and refreshment facilities. Finally, the need of a pleasant experience must be fulfilled and this is influenced by visual aspects such as architecture, design, cleanliness, interior finish materials and colours. Besides these, however, also less tangible environmental variables, such as (day) light, smell and sound (noise or music) influence the quality of the experience [10]. Offering facilities such as shops and cafés and the obvious presence of staff enhances a pleasant stay. Fig. 2 shows the hierarchy in interests of the various quality dimensions. At a station passengers are either moving or staying. When travellers are moving, speed and ease are key, but when they are staying, like during a wait or sitting in a riding train, then comfort and experience are vital $[8,9,11,12]$. In this respect, speed and ease are dissatisfiers, in which these quality aspects are rated negatively, if they do not meet expectations [13-15]. For passengers safe, reliable, easy and speedy journeys are the bedrock of transportation; they are generic and apply to each transport interchange. Comfort and experience are satisfiers $[14,16]$. They are noticed when the journey is evaluated positively, albeit that the interpretation can vary per passenger. In short: the base of the pyramid (dissatisfiers) is about time well saved and the top of the pyramid (satisfiers) is about time well spent.

\section{Improving Customer Satisfaction: Cases of Two Approaches of Improvement}

The challenge in planning and design of train services is to find the most efficient (set of) design choices. Depending on the context this might either mean focusing on the top or on the bottom of the pyramid. Let's for instance look at disturbances: A disruption or a sudden rush can lead to discomfort and negative emotions, like stress and anger. When a disruption takes place staff has to respond well in the moment of truth, e.g. by taking the concerns of the customers seriously by immediately offering them sufficient and topical information. The external 
pressure resulting from a disruption can lead to negative emotions and negatively influence the perception of quality. Another way of enhancing the processes in the bottom of the pyramid, is an improved planning process, as a lot of disruptions and irregularities can be foreseen in the planning stage. Adding slack and applying a holding regime are valuable methods to improve service reliability (see e.g. Ref. [17]). In addition, rescheduling measures are potential options to improve the level of service (see e.g. Ref. [18]).

In this section we show two approaches of quality improvements of public transport, starting with focus on dissatisfiers, namely service reliability.

\subsection{Improving Service Reliability}

Literature shows that in public transport substantial attention is given to ways to improve service reliability at the operational level. The implementation of bus lane schemes and traffic signal priority are the most used solutions in this field (as shown by e.g. Ref. [19]. More detailed research on the impacts of priority and bus lanes may be found in for instance [20]. Similar to priority, for instance, Refs. [21] and [22] give an overview of the issues which need to be considered in synchronization.

It is not clear how and to what extent strategic and tactical design decisions in public transport systems might affect service reliability. We are looking for instruments improving service reliability in public transport at the tactical and strategic level, since in practice much attention is already paid to operational instruments.

The instruments we are looking for should offer good possibilities to improve service reliability and should be less researched so far. Van Oort and Van Nes [23] showed that some design instruments are already common practice (for instance traffic light priority and exclusive lanes). But even with the application of these instruments, service variability is still substantial. The instruments which we investigated are

(1) Trip time determination;

(2) Vehicle holding;

(3) Terminal design;

(4) Line coordination;

(5) Line length design.

The main results are presented in this section. More details may be found in Refs. [24-28].

The selected instruments adjust the process of public transport thereby being a regulator in the feedforward loop. Fig. 3 shows the feedforward loop, with the addition of the strategic and tactical instruments. To achieve a high level of service reliability, this feedforward loop should be applied.

To apply the feedforward loop, shown in Fig. 3, it is necessary that at the strategic and tactical design, a forecast of the expected disturbances is possible. This will be done by prediction tools (based on monitored data), as for instance described in Kanacilo and Van Oort [29] and Van Oort et al. [30]. In addition, the impacts of the disturbances on passengers, the expected level of service reliability, should be predicted as well. In this way, an iterative improvement process of the regulator is possible, optimizing the impact of passengers.

The terminal design instrument relates to (new) rail lines with tail tracks as terminal or short-turning facilities. For high-frequency, distributed lines, we recommend compact tail tracks with double crossovers directly after the stop. Concerning (new) lines with a clear break point in passenger pattern, we recommend to split the line or to apply holding points. For long-headway services we propose to use the 35 -percentile value for scheduled trip time. And if parts of lines are very crowded, we suggest investigating the effects of coordination.

Table 1 summarizes the indicative conclusions of the tentative cost-effectiveness assessment of the five instruments analysed. The costs are divided into infrastructure costs and operating costs. Travel time costs of passengers are considered as benefits, since all 


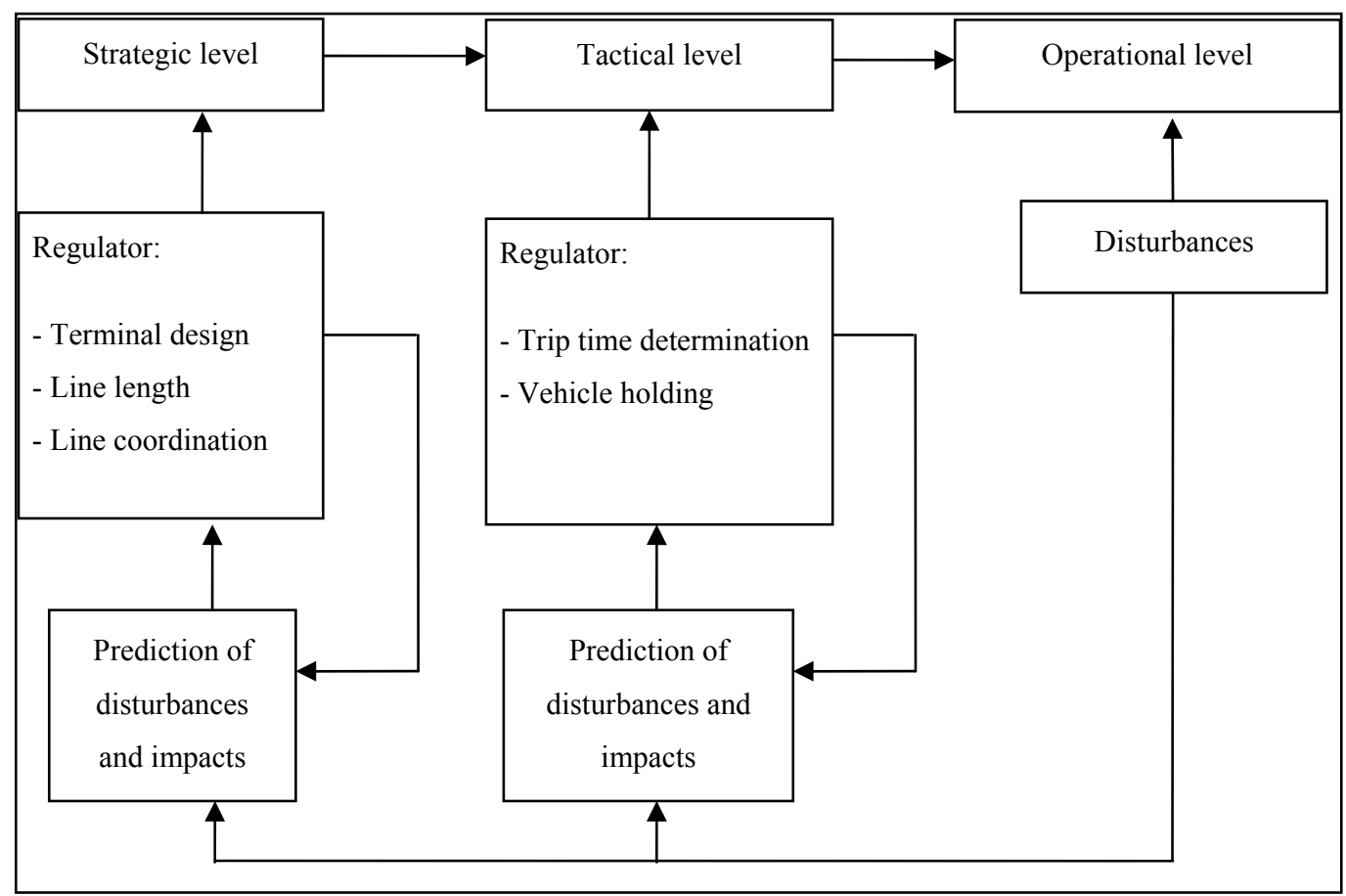

Fig. 3 Feedforward loop in public transport planning, including our investigated instruments at strategic and tactical level.

our instruments reduce passenger travel time. While infrastructure costs mainly arise at the start of the project, operating costs occur during the complete period of operations. The benefits consist of additional travel time and time variability savings for passengers and additional revenues for the operators and public transport authority. In Table 1, it is only indicated whether costs occurs (much (--) or less (-) extra costs), savings are possible (much $(++)$ or less $(+)$ savings) or no impacts arise (0). Since local characteristics are very important, a bandwidth is provided. Since all instruments may yield reduced additional travel time (variability) and increased ridership and revenues, the benefits are indicated correspondingly by a + or ++ .

In the cases of vehicle holding, coordination and line length, the impacts of the instrument depend on other variables as well and therefore these instruments do not always yield positive results. In that case a "0" is indicated. To get a general view on the economics of the instrument, the result of costs and revenues are generally indicated, taking the bandwidth and probability of both into account.

Table 1 shows that both tactical instruments have a clear positive balance whereas the strategic instruments show a more scattered result. Whether these latter instruments are cost beneficial strongly depends on other factors as well. Optimizing terminal design is beneficial for passengers, but may require higher costs compared to traditional design. However, we showed that the costs per year are much less than the benefits. Coordination and shorter lines may be effective, but the effects depend on for instance deviations' and passengers' characteristics.

We confronted the benefits of the planning instruments introduced above with their costs to assess the added value of each of the instruments. In the assessment we focus on the difference between the situations with and without the instrument applied. The costs consist of infrastructure and operating costs; the benefits are expressed as the reduced (additional) travel time due to reduced service variability [31]. We translated these into welfare gains for both new and existing passengers. The expected increase of ridership is presented as well as an indication of additional revenues. To get an impression of these benefits, an estimate has been made of how beneficial the instruments 
Table 1 Tentative cost-effectiveness assessment.

\begin{tabular}{llllll}
\hline Instrument & Infrastructure costs & Operating costs & Passenger benefits & Operator revenues & Total \\
\hline 1. Trip time determination & 0 & 0 & ++ & ++ & ++ \\
2. Vehicle holding & 0 & 0 & $++/+/ 0$ & $++/+/ 0$ & $++/+/ 0$ \\
3. Terminal design & $0 /-/-$ & $+/ 0$ & + & + & $+/ 0$ \\
4. Coordination & 0 & $0 /-$ & $+/ 0$ & $+/ 0$ & $+/ 0$ \\
5. Line length & $0 /-/--$ & $+/ 0 /-$ & $+/ 0$ & $+/ 0$ & $+/ 0$ \\
\hline
\end{tabular}

in The Hague area, in the Netherlands, based on an assessment of how many lines and which time periods (e.g. peak vs. non-peak hours) may be improved.

Since we will calculate the reduction of the average additional travel time per passenger per instrument, we are able to estimate the benefits using existing techniques to assess travel time benefits and increased ridership. The analysis presented is on an aggregated level, in which the total effects for all passengers are estimated. The following relationships and assumptions are used in this assessment:

- We focus on passengers travelling from stop to stop on a single line (including waiting).

- Transferring is not incorporated explicitly, but is assumed to be the start of a new journey.

- Access and egress time are assumed not to be affected. The average passenger journey (in a 100\% reliable situation) consists of 9 minutes in-vehicle time and 2 minutes of waiting time at the stop. The access and egress time sum up to 5 minutes. These numbers are based on characteristics of the urban public transport in The Hague;

- A decrease in passenger travel time (stop to stop, including waiting) of $1 \%$ will lead to ridership increase of $0.5 \%$ [32] (i.e., a demand elasticity of travel time of $-0.5)$

- To incorporate passenger perception of travel time components, the weights as shown in Equations 1 and 2 are used, based on Van Der Waard [33].

$$
\begin{gathered}
E\left(\widetilde{T}_{l, j-k}^{\text {journey,perc }}\right)=E\left(\widetilde{T}_{l, j-k}^{\text {journey,sched }}\right)+ \\
\theta_{\text {waiting }} * E\left(\widetilde{T}_{l, j}^{\text {add,waiting }}\right)+\theta_{\text {in-vehicle }} * E\left(\widetilde{T}_{l, j-k}^{\text {add in-vehicle }}\right)+ \\
\theta_{\text {waiting }, R B T} * R B T_{l, j}^{\text {waiting }}+\theta_{\text {in-vehicle } R B T} * R B T_{l, j-k}^{\text {in-vehicle }}(1)
\end{gathered}
$$

$$
E\left(\widetilde{T}_{l, j-k}^{\text {journey, sched }}\right)=E\left(\widetilde{T}_{l, j}^{\text {sched, waiting }}\right)+T_{l, j-k}^{\text {sched, in-vehicle }}
$$

where:

$\widetilde{T}_{l, j-k}^{\text {journey,perc }}=$ perceived passenger travel time from stop $j$ to stop $k$ on line $l$;

$\widetilde{T}_{l, j-k}^{\text {journey,sched }}=$ total passenger travel time according to schedule (on line $l$ departing at stop $j$ and arriving at stop $k$ );

$\widetilde{T}_{l, j}^{\text {Add,waiting }}=$ additional waiting time per passenger due to unreliability of line $l$ at stop $j$;

$\widetilde{T}_{l, j-k}^{\text {add, in-vehicle }}=$ additional in-vehicle time due to service variability between stop $j$ and $k$ on line $l$;

$R B T_{l, j}^{\text {waiting }}=$ Reliability Buffer Time at stop $j$ on line $l$ due to variability in waiting time;

$R B T_{l, j-k}^{\text {in-vehicle }}=$ Reliability Buffer Time between stop $j$ and $k$ on line $l$ due to variability in in-vehicle time;

$\theta_{\text {waiting }}=$ relative weight of additional waiting time;

$\theta_{i n-v e h i c l e}=$ relative weight of additional in-vehicle time;

$\theta_{\text {waiting, } R B T}=$ relative weight of RBT of waiting time;

$\theta_{i n-v e h i c l e, R B T}=$ relative weight of RBT of in-vehicle time;

$\widetilde{T}_{l, j}^{\text {sched,waiting }}=$ waiting time according to the schedule per passenger at stop $j$ on line $l$;

$T_{l, j-k}^{\text {sched, in-vehicle }}=$ in-vehicle time (stop $j-k$ ) on line $l$ per passenger according to the schedule.

We roughly estimated the costs of unreliability at $€ 12$ million per year in The Hague. We assessed the 
effectiveness of the planning instruments for The Hague and we estimated a possible reduction of these costs of $€ 8$ million per year when the instruments are applied on the potential lines and during the time in which they may be beneficial. The combination of effects of all instruments applied together has been assessed as well. The costs are expected to be maximum $€ 3$ million per year. This demonstrates the added value of implementing the planning instruments. In addition, it is important to note that the impacts generally are underestimated, since the reduction of the variability of the additional travel time has not yet been estimated explicitly. However, all instruments we introduced will reduce this variability to some extent and since passengers consider this variability $40 \%$ more valuable than travel time [31], we made a rough estimate that the actual costs of service unreliability and the potential savings are at least twice as high.

\subsection{Improving Experience}

The previous section showed examples to improve service quality focusing on the bottom of the pyramid. The other dimension of quality improvements in public transport is quality perception of passengers. When customers are asked about the relative importance of the softer service qualities, like the attitude of staff or the ambience of the service environment as compared to more objective variables such as travel time, opening hours, parking etcetera, it often ends up at the bottom of the list. However, with in-depth interviews and associative techniques it becomes clear that the role of the qualities in the top of the pyramid is far more important than passengers themselves realize [10, 34-36]. This is where psychology comes in: it exposes that which respondents apparently have difficulty in cognitively articulating, i.e. how important the total service is to them.

\subsubsection{How Does Experience Work?}

People's behaviour is influenced by numerous stimuli in the environment, often unconsciously. Over $95 \%$ of environmental stimuli such as sound, temperature, colour and smell are experienced unconsciously, although they can significantly influence our emotions and therefore our behaviour [36]. This is illustrated in Fig. 4.

The stimuli in the environment can lead to two types of behaviour: approach or avoidance. Negative emotions lead to avoidance behaviour and positive emotions lead to approach behaviour. Avoidance behaviour is all the negative behaviour provoked by the environment, i.e. wanting to leave, not wanting to explore, lack of connection with the place and no desire to return. Approach behaviour is all the positive behaviour provoked by the environment, such as wanting to stay, setting out to explore the environment, feeling connected to the place, desire to spend money and to return. Approach behaviour can be stimulated by consciously chosen design and deliberate addition of the right (intangible) stimuli to the environment. Think, for a moment, about colours, sounds and smells you might experience during a journey. So, emotions play a pivotal role in behaviour and the right environmental stimuli are the key to influence those emotions.

\subsubsection{Three Management Dimensions}

A train journey is a service, not a product. The difference between a product (e.g. a car) and a service is that a service is provided and consumed all at the same time. Customers, therefore, find themselves 'in the factory' and experience the service within the physical facilities of the service environment. The environment is therefore the packaging of the service,

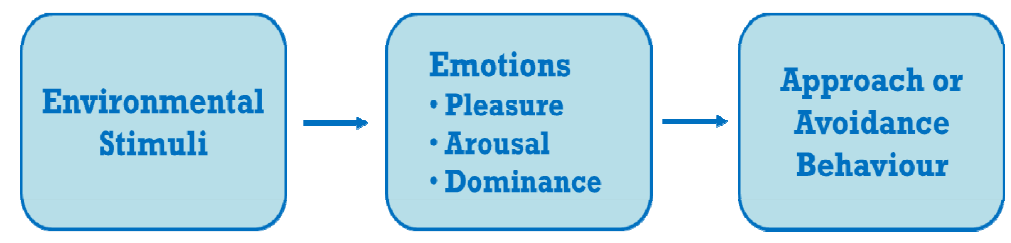

Fig. 4 Stimulus-Organism-Response model [37]. 
which is why it is of such importance in the total customer experience. The experience of a service can be managed in three interrelated dimensions [38]:

(1) The service provision processes,

(2) The people present (staff and customers) and

(3) The service environment (place).

The processes have a strongly time-bound nature and efficiency is key: the more efficient and flexible the service provision process runs, the more satisfied customers will be. The presence of sufficient, competent staff also influences customer satisfaction in a positive sense, just as the amount and attitude of other people in the service environment; too many or too few customers can lead to negative emotions. Finally, the service environment strongly influences the perception of the quality of the service. A dirty, chaotic, smelly or noisy environment leads to negative emotions, whereas a clean, inviting and quiet environment leads to positive emotions.

Fig. 5 shows the three quality dimensions of a service which are interrelated. It is clear that the processes take place at the base of the pyramid and the service environment (space) and staff (people) are mainly to be found on the satisfiers side at the top of the pyramid. The excellent performance of processes leads to satisfied passengers. You can go a step further and make your passengers truly happy by offering a perfect service environment with passionate staff.

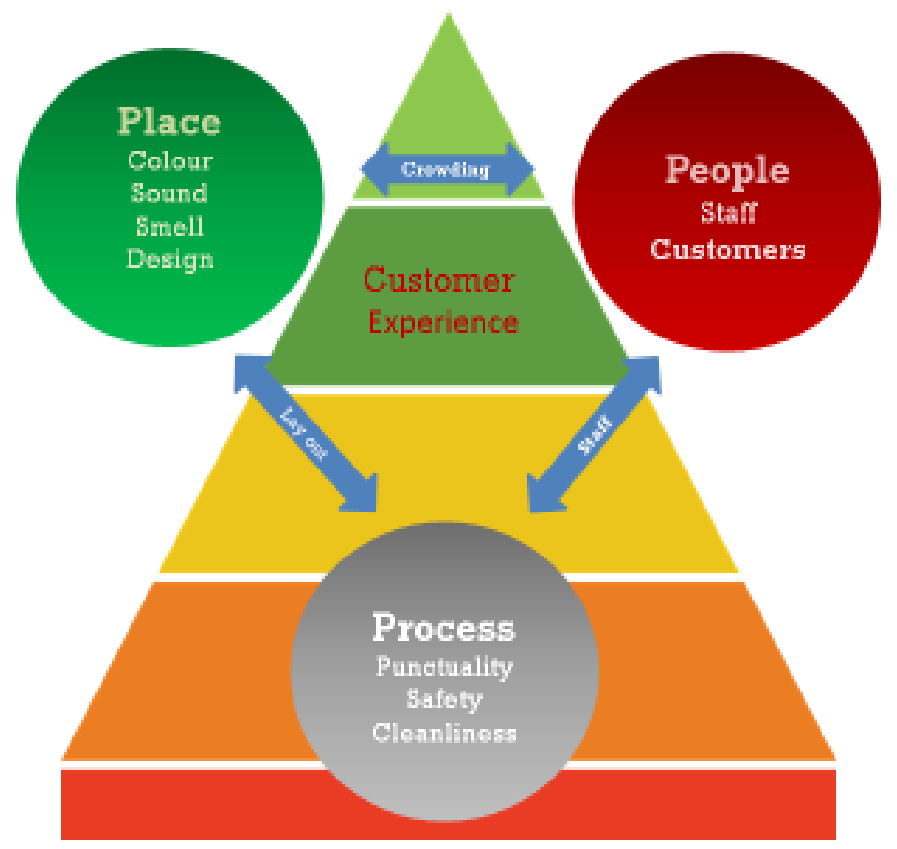

Fig. 5 The three management dimensions of a service.

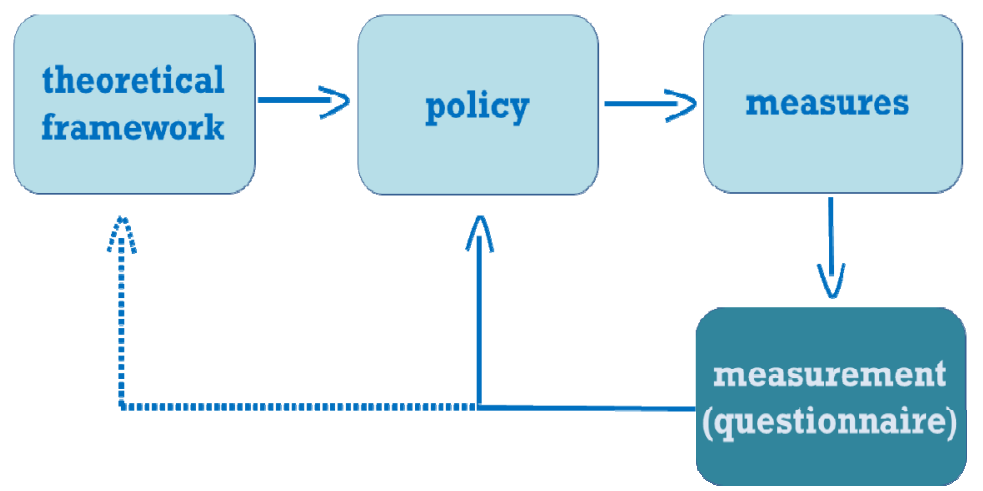

Fig. 6 Evidence based design: the learning curve for quality improvement. 


\subsubsection{Measuring All Relevant Quality Aspects}

Based on the customer needs of the Pyramid, the Dutch railways (NS) have designed measuring instruments for stations and trains respectively known as the Station Experience Monitor (SEM) and Train Experience Monitor (TEM). To enhance the quality of the service NS uses the approach of evidence based design. The TEM and the SEM are at the heart of this management cycle. The TEM/SEM is a short self-completed questionnaire in which passengers on the train or at the platform of a station are asked to answer various questions about the quality aspects of their train journey or stay at the station $[39,40]$. The innovation of these questionnaires is that they pay specific attention to all the quality layers of the Pyramid. So, for example, not only questions related to the functionality of the travel process are asked, like safety, cleanliness and the provision of information, but also questions related to the experience are collected, like the comfort (amenities, inviting) or ambiance (colours, sounds, light, design) of the station or the train. Based on these actual customer insights, policy is made, leading to targeted improvement changes. The effects of those changes are measured using the TEM and SEM tool, so that the degree of improvement can be determined and policy can be adjusted and refined as necessary (see Fig. 6).

When enhancing the quality experience of the train journey, in order to obtain higher rates from customers, it is key to first pay attention to the basic qualities (dissatisfiers) of the train journey. They have to be at least at an acceptable level and then we can pay attention to the satisfiers [41]. Where the goal of traditional research is creating higher scores by making sure that the process of riding trains is becoming more reliable, the SEM and the TEM also focus on creating higher appreciation on satisfiers: the attitude of people and the quality of the service environment. In other words: using a ten point scale ( 1 is very bad and 10 is very good) it is important to realize that dissatisfiers need to be minimized, no score lower than a 5 , and the satisfiers need to be maximized, preferably scores higher than an 8.

The SEM and the TEM can be used as a monitor to measure the development of the scores in time or for measuring the impact of new measures in $\mathrm{AB}$ testing, that will say measuring the old situation (A) and compare that with the new situation (B), the difference shows the impact of the adjustment. We will now put the theory into practice by showing the results of some examples in practice. First we will show an example of the SEM as a monitor and then give an example of the TEM in AB testing.

3.2.4 Case Study Station Design: Modernization of Rotterdam Central Station

Rotterdam central Station needed a modernization, due to increasing footfall and the arrival of High Speed Trains. Research insights to enhance the customer experience were used to get a good design and get the best results for the customer. The station is designed to have a good overview and short walking distances and attention is paid to create a warm ambience. This is done by the use of natural materials like wooden benches and a wooden roof in the concourse, a red (warm color) natural stone floor in the concourse and on the platform, lots of shops and amenities between the escalators to the platforms, and a large video screen with movies of the sea harbor of Rotterdam which expresses the couleur locale. In March 2014 the station was officially opened; Fig. 7 shows the old and new situation.

NS and Prorail (the Dutch rail infrastructure manager) use the SEM to measure the 50 largest stations of the Netherlands every three month and as an example the development of the general score of Rotterdam Central Station is shown in Fig. 8. The figure shows clearly a sudden increase in the score by the opening of main parts of the station in 2012 and even higher by the complete opening in 2014. The scores remain at a high level and a recent benchmark study comparing the quality of 26 large international train station worldwide shows that Rotterdam Central 

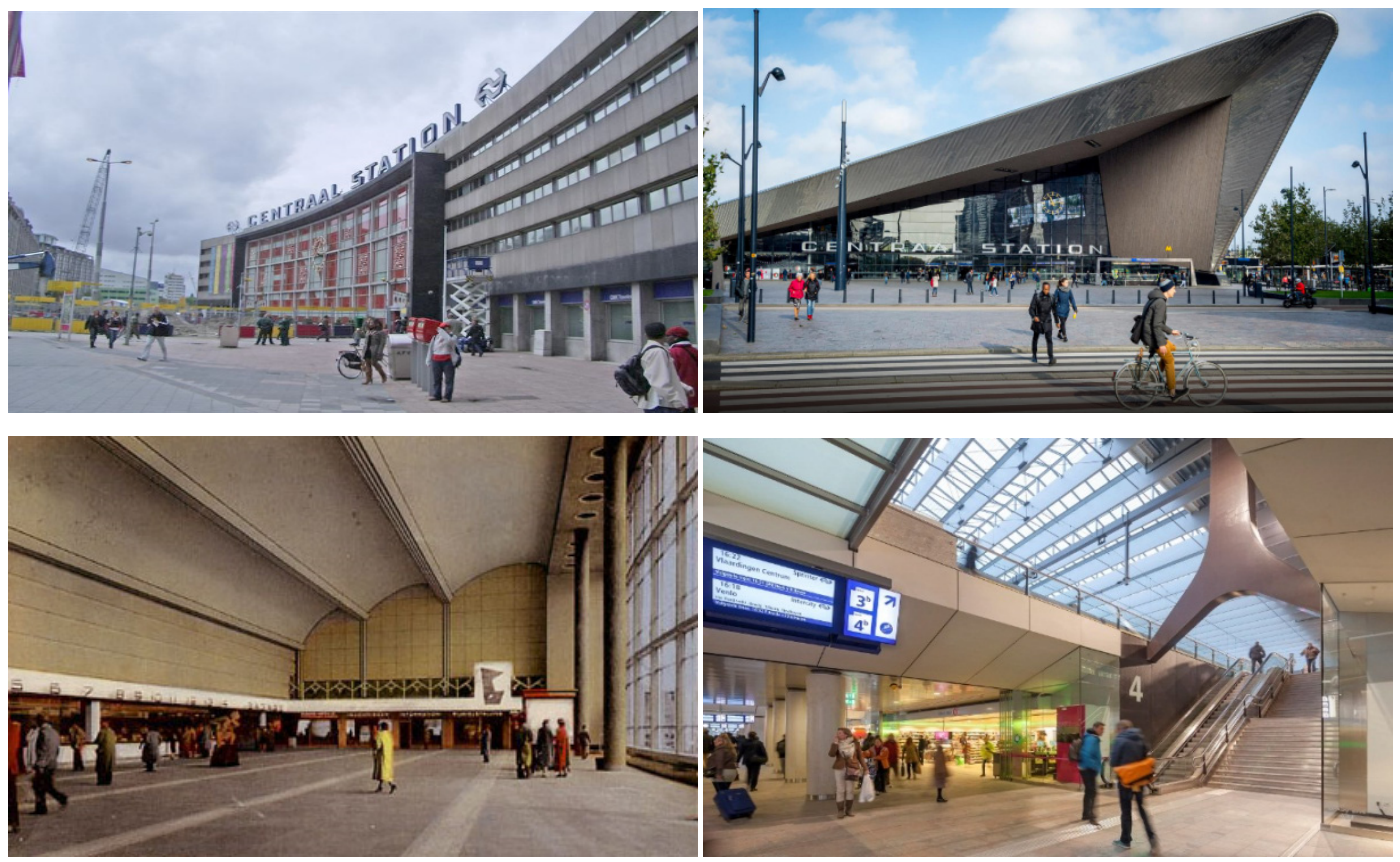

Fig. 7 Rotterdam Central Station (left old station, right new station).

\section{General Score Station Rotterdam}
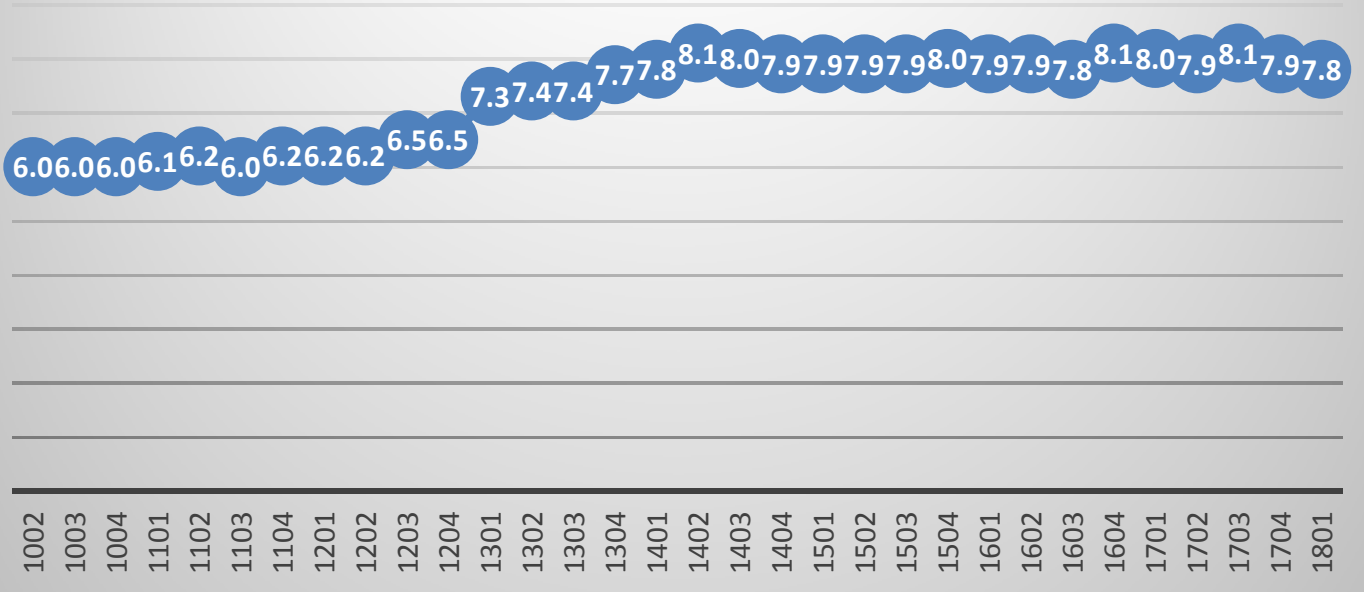

Fig. 8 Development of general score of Rotterdam Central Station (X-axes: year and quarter, Y-axes, overall score station; 1 $=$ very bad, $10=$ very good).

Station is the fifth best station of the world and is even better appreciated than St Pancreas in London [42].

3.2.5 Case Study Train Design: Modernization of a Double-decker Train

Based on customers' insights, NS has recently modernised an old double-decker unit (VIRM1) and renamed it VIRMm1 ( $\mathrm{m}$ stands for modernized). A great deal of attention was being paid to design, fresh colours and small, yet high-level, details (Fig. 9 top left old train, other new train).

The results of the modernization are shown in Fig. 10. The average score for all aspects is significantly higher for the modernized unit. The customer evaluations show a considerable increase in 

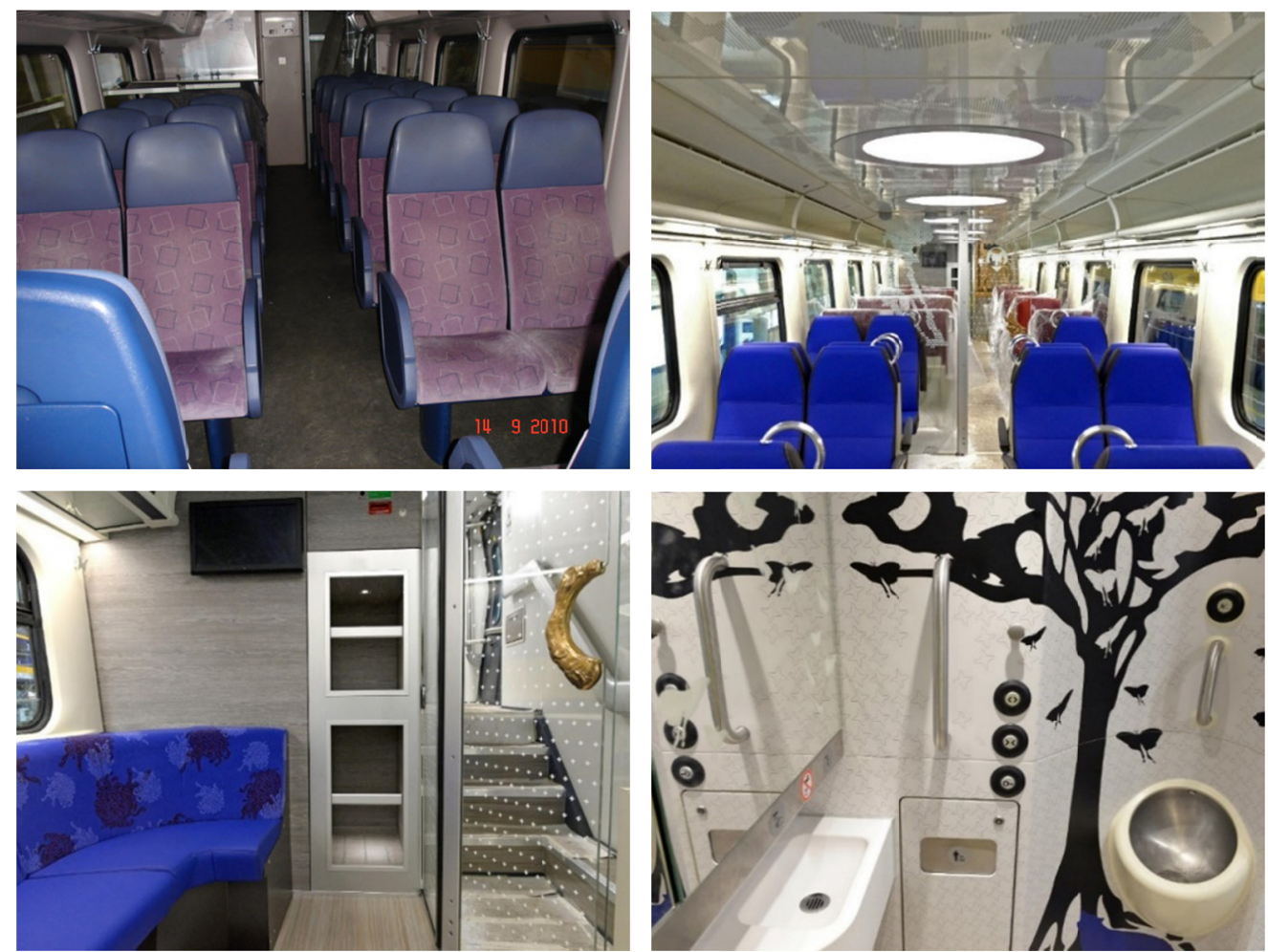

Fig. 9 Examples modernisation old double-decker train (top left VIRM1 to VIRMm1 three other pictures).

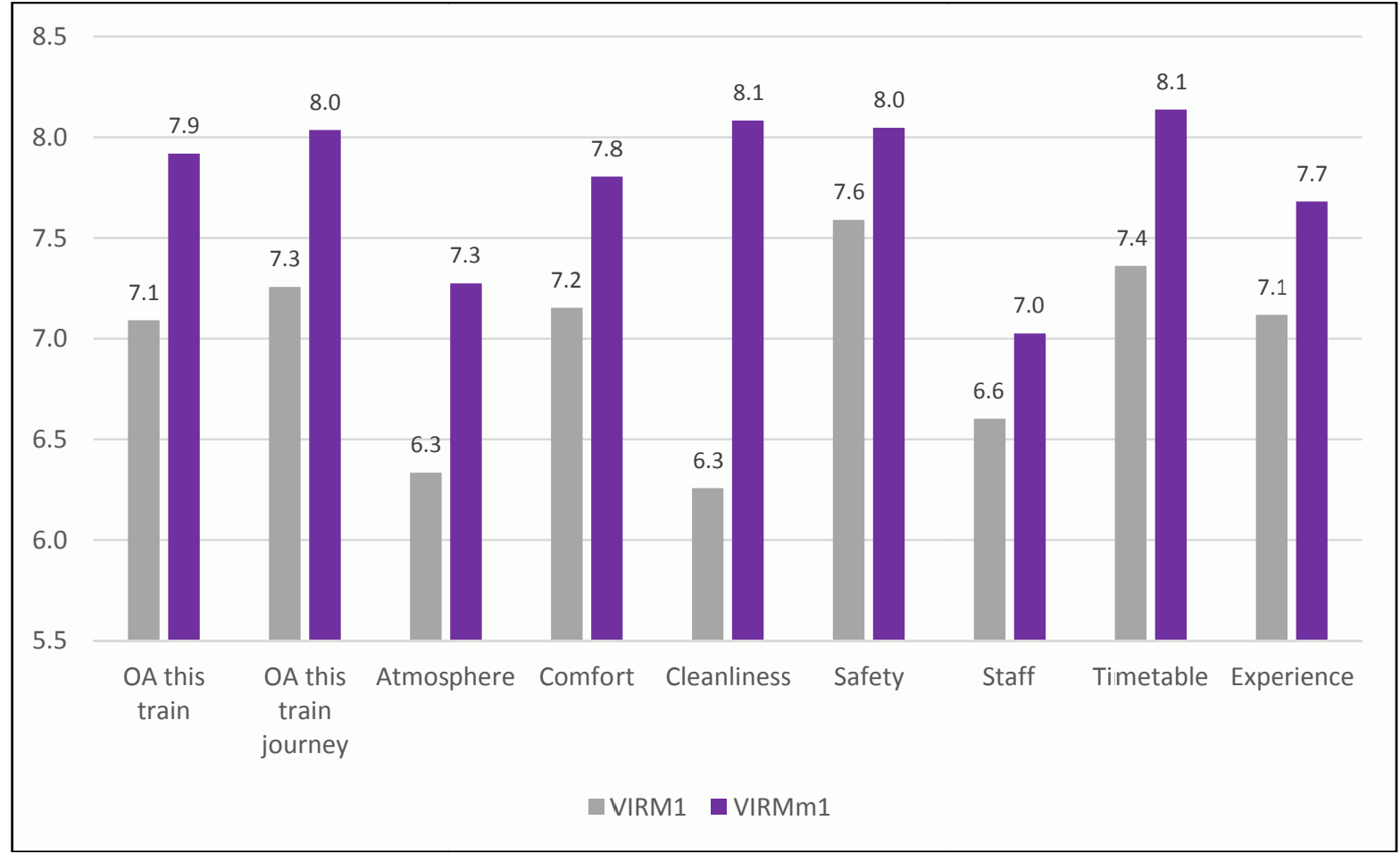

Fig. 10 Results Modernisation of old double-decker train (VIRM1 to VIRMm1). 
the Overall Assessment of the Train, the Atmosphere and Cleanliness.

3.2.6 Importance of Quality Aspects of Trains and Stations

The Overall Assessment Measurement of a train journey is the final evaluation of the customer experience. After undertaking statistical (regression) analyses on the data from different train journeys we discovered that the train itself contributes the most $(60 \%)$ to the overall assessment of the train journey. This is followed by the contribution of running trains on time (time table, $30 \%)$ and staff $(10 \%)$. It is obvious that the experience of the train itself has the greatest influence on the Overall Assessment Measurement of the train journey. Also for stations, regression analyses show that dissatisfiers are responsible for explaining almost half of the total score of the station and satisfiers are responsible for the other half of the scores passengers give for the station $[39,43]$.

\section{Conclusions}

In this paper we showed how passengers perceive public transport quality. We distinguish both satisfiers and dissatisfiers and demonstrated that both can be improved. The challenge in planning and design is to find the most efficient (set of) measure(s) and depending on the context this might either mean focusing on the top or on the bottom of the pyramid.

Concerning improving dissatisfiers, we showed 5 examples of measures to improve service reliability. A tentative cost-effectiveness assessment showed that the tactical instruments (trip determination and vehicle holding) are cost-effective in almost every case. Their benefits are substantial and the costs are nil. These instruments should be considered in the design of every public transport system. However, the vehicle holding instrument is only beneficial if the passenger pattern has a clear break point and trip time determination only is relevant in long-headway services. It is presented that strategic instruments have considerable benefits as well. Optimized terminal design enables enhanced service reliability. Coordination and shorter lines may result in reduced passenger travel times as well. However, these instruments may look costly due to necessary additional infrastructure and or (occasionally) additional vehicles.

Concerning satisfiers, the Dutch railways (NS) uses the approach of evidence based design to enhance the quality experience of the passengers and uses measurement instruments which are able to measure aspects of the base and the bottom of the pyramid. But at stations and trains the experience of the quality of the service environment is the most important factor for enhancing the experienced quality of a station or a train trip. The good news is that investments in the service environment do not only have a high impact on customer scores and positive behaviour, but also cots much less then investments in the service process. We also found that influencing and enhancing the qualities of the satisfiers is far more important than traditional studies showed us. For stations, regression analyses show that dissatisfiers are responsible for explaining almost half of the total score of the station and satisfiers are responsible for the other half of the scores passengers give for the station. We still have to put a lot of energy in getting the basics right, starting in the planning phase, but then we are not allowed to lean back. We have to keep investing in qualities like ambience, comfort and experience which makes the customers truly happy at the end of the day.

\section{References}

[1] Turnquist, M. A., and Bowman, L. A. 1980. "The Effects of Network Structure on Reliability of Transit Service." Transportation Research Part B 14: 79-86.

[2] Van Hagen, M., and Bron, P. 2014. "Enhancing the Experience of the Train Journey: Changing the Focus from Satisfaction to Emotional Experience of Customers." Transport Research Procedia: 253-63.

[3] Van Hagen, M., and de Bruyn, M. 2015. "Emotions during a Train-Journey Quantified.” Paper presented on European Transport Conference, Frankfurt.

[4] Jain, J., and Lyons, G. 2008. "The Gift of Travel Time." The Journal of Transport Geography 16 (2): 81-9. 
[5] Warffemius, P., van Hagen, M., de Bruyn, M., Bakker, P., and van der Waard, J. 2016. "The Value of Comfort in Train Appraisal.” Paper presented on European Transport Conference, Barcelona.

[6] Maslow, A. H. 1954. Motivation and Personality. New York: Harper \& Brothers.

[7] Peek, G. J., and Van Hagen, M. 2002. "Creating Synergy in and around Stations: Three Strategies. Transport Research Board." Journal of Transportation Research Record 1793: 1-6.

[8] Pruyn, A. T. H., and Smidts, A. 1998. "Effects of Waiting on the Satisfaction with the Service: Beyond Objective Time Measures.” International Journal of Marketing 15: 321-34.

[9] Tom, G., and Lucey, S. 1997. "A Field study Investigating the Effect of Waiting on Customer Satisfaction." The Journal of Psychology 131 (6): 655-60.

[10] Van Hagen, M. 2011. "Waiting Experience at Train Stations." Dissertation, Eburon, Delft (NL).

[11] Wakefield, K. L., and Blodgett, J. G. 1994. "The Importance of Servicescapes in Leisure Service Settings." Journal of Services Marketing 8 (3): 66-76.

[12] Wakefield, K. L., and Blodgett, J. G. 1999. "Customer Response to Intangible and Tangible Service Factors." Psychology \& Marketing 16 (1): 51-68.

[13] Friman, M., and Gärling, T. 1999. "Frequency of Negative Critical Incidents and Satisfaction with Public." Paper presented on Urban Transport Systems Conference, Lund University, Sweden.

[14] Herzberg, F., Mausner, B., and Snyderman, B. B. 1959. The Motiovation to Work (2nd ed.) New York: John Wiley \& Sons.

[15] Zeithaml, V. A., Berry, L. L., and Parasuraman, A. 1993. "The Nature and Determinants of Customer Expectations of Service." Journal of the Academy of Marketing Science 21 (1): 1-12.

[16] Johnston, R. 1985. "The Determinants of Service Quality: Satisfiers and Dissatisfiers." International Journal of Service Industry Management 6: 53-71.

[17] Hickman, M. 2001. "An analytical Stochastic Model for the Transit Vehicle Holding Problem." Transportation Science 35 (3): 215-37

[18] Mirchandani, P. B., Li, J. Q., and Hickman, M. 2010. “A Macroscopic Model for Integrating Bus Signal Priority with Vehicle Rescheduling." Public Transport 2 (3): 159-72.

[19] Levinson, H. S., and St. Jacques, K. R. 1998. "Bus Lane Capacity Revisited." Transportation Research Record 1618: 59-65.

[20] Kittelson \& Assoc, Inc., Parsons Brinckerhoff, Inc., KFH Group, Inc., Texam A\&M Transportation Institute, \& Arup. 2013. Transit Capacity and Quality of Service
Manual (3rd ed.). Transit Cooperative Highway Research Program (TCRP) Report 165, published by Transportation Research Board, Washington.

[21] Ceder, A. 2007. Public Transit Planning and Operation, Theory, Modelling and Practice. Technion-Israel Institute of Technology, Haifa.

[22] Lee, A., van Oort, N., and van Nes, R. 2014. "Service Reliability in a Network Context." Transportation Research Record 2417: 18-26.

[23] Van Oort, N., and van Nes, R. 2009a. "Control of Public Transport Operations to Improve Reliability: Theory and Practice." Transportation Research Record 2112: 70-6.

[24] Van Oort, N., and van Nes, R. 2009b. "Line Length versus Operational Reliability: Network Design Dilemma in Urban Public Transportation." Transportation Research Record 2112: 104-10.

[25] Van Oort, N., and van Nes, R. 2009c. "Regularity Analysis for Optimizing Urban Transit Network Design.” Public Transport 1 (2): 155-68.

[26] Van Oort, N., and van Nes, R. 2010. "The Impact of Rail Terminal Design on Transit Service Reliability." Transportation Research Record 2146: 109-18.

[27] Van Oort, N., Boterman, J. W., and van Nes, R. 2012. "The Impact of Scheduling on Service Reliability: Trip-time Determination and Holding Points in Long-headway Services." Public Transport 4 (1): 39-56.

[28] Van Oort, N., Wilson, N. H. M., and van Nes, R. 2010. "Reliability Improvement in Short Headway Transit Services: Schedule-based and Headway-based Holding Strategies." Transportation Research Record 2143: 67-76.

[29] Kanacilo, E. M., and Van Oort, N. 2008. "Using a Rail Simulation Library to Assess Impacts of Transit Network Planning on Operational Quality." In Computers in Railways XI, edited by Allen, J., Arias, E., Brebbia, C. A., Goodman, C. J., Rumsey, A. F., Sciutto G., and Tomii, N. Southampton, UK: WITpress, 35-44.

[30] Van Oort, N., Brands, T., de Romph, E., and Yap, M. 2016. "Ridership Evaluation and Prediction in Public Transport by Processing Smart Card Data: A Dutch Approach and Example.” In Public Transport Planning with Smart Card Data, edited by Kurauchi, F., and Schmöcker, J. D. CRC Press, Chapter 11.

[31] Van Oort, N. 2016. "Incorporating Enhanced Service Reliability of Public Transport in Cost-benefit Analyses." Public Transport 8 (1): 143-60.

[32] Balcombe, R., Mackett, R., Paulley, N., Preston, J., Shires, J., Titheridge, H., Wardman, M., and White, P. 2004. The Demand for Public Transport: A Practical Guide. TRL Report, TRL 593.

[33] Van Der Waard, J. 1988. "The Relative Importance of Public Transport Trip Time Attributes in Route Choice." 
In Proceedings of PTRC, London.

[34] Dickson, J., and Albaum, G. 1977. "A Method for Developing Tailormade Semantic Differentials for Specific Marketing Content Areas.” Journal of Marketing Research 14: 87-91.

[35] Donovan, R., and Rossiter, J. 1982. "Store Atmosphere: An Environmental Psychology Approach.” Journal of Retailing 58: 34-57.

[36] Zaltman, G., and Coulter, R. H. 1995. "Seeing the Voice of the Customer: Metaphor-Based Advertising." Research Journal of Advertising Research 35 (4): 35-51.

[37] Mehrabian, A., and Russell, J. A. 1974. "An Approach to Environment Psychology." Journal of Marketing 46 (2): 86-91.

[38] Bitner, M. J. 1992. "Servicescapes: The Impact of Physical Surroundings on Customers and Employees." Journal of Marketing 56: 57-71.
[39] Van Hagen, M. 2015. "Effect of Station Improvement Measures on Customer Satisfaction." Journal of Traffic and Transportation Engineering 1 (2): 7-18.

[40] Van Hagen, M., and Sauren, J. 2013. "Influencing the Train Experience: Using a Successful Measurement Instrument." In ETC Proceedings.

[41] Van Hagen, M., and De Bruyn, M. 2012. "The Ten Commandments of How to Become a Customer-driven Railway Operator." Paper presented on European Transport Conference, Glasgow.

[42] Bras, J., and Bollinger, B. 2018. Improving Quality of Life through Transit Hubs. Delivering City Value and Prosperity with Mobility Oriented Developments. Report Arcadis.

[43] Van Hagen, M., and Foljanty, K. 2017. "The Quality of a Transport Interchange through the Eyes of Passengers." In Journeys. Land Transport Authority, Academy Singapore. 